\title{
Tet methylcytosine dioxygenase 2 inhibits atherosclerosis via upregulation of autophagy in ApoE-/- mice
}

\author{
Juan Peng ${ }^{1, *}$, Qin Yang ${ }^{1, *}$, A-Fang Lii,*, Rong-Qing Li ${ }^{1}$, Zuo Wang ${ }^{1}$, Lu-Shan Liu ${ }^{1}$, \\ Zhong Ren ${ }^{1}$, Xi-Long Zheng ${ }^{2}$, Xiao-Qing Tang ${ }^{3}$, Guo-Hua Li ${ }^{1}$, Zhi-Han Tang ${ }^{1}$, Zhi- \\ Sheng Jiang ${ }^{1}$ and Dang-Heng Wei ${ }^{1}$ \\ 1. Institute of Cardiovascular Disease, Key Lab for Arteriosclerology of Hunan Province, University of South China, Hengyang, \\ Hunan, China \\ 2. Department of Biochemistry and Molecular Biology, The Libin Cardiovascular Institute of Alberta, The University of Calgary, \\ Health Sciences Center, Calgary, Alberta, Canada \\ 3. Department of Physiology \& Institute of Neuroscience, Medical School, University of South China, Hengyang, PRC, China \\ * Co-first author
}

Correspondence to: Zhi-Han Tang, email: tangzhihan98@163.com

Zhi-Sheng Jiang, email: zsjiang2005@163.com

Dang-Heng Wei, email: weizhonghua99@126.com

Keywords: TET2, autophagy, endothelial cells, inflammation, atherosclerosis, Pathology Section

Received: June 08, $2016 \quad$ Accepted: October 21, $2016 \quad$ Published: November 04, 2016

\section{ABSTRACT}

Tet methylcytosine dioxygenase 2 (TET2) mediates the conversion of 5 -methylcytosine $(5 \mathrm{mC})$ to 5 -hydroxymethylcytosine $(5 \mathrm{hmC})$. The loss of TET2 is associated with advanced atherosclerotic lesions. Our previous study showed that TET2 improves endothelial cell function by enhancing endothelial cell autophagy. Accordingly, this study determined the role of TET2 in atherosclerosis and potential mechanisms. In ApoE ${ }^{-/-}$mice fed high-fat diet, TET2 overexpression markedly decreased atherosclerotic lesions with uniformly increased level of $5 \mathbf{h m C}$ and decreased level of $5 \mathrm{mC}$ in genomic DNA. TET2 overexpression also promoted autophagy and downregulated inflammation factors, such as vascular cell adhesion molecule 1, intercellular adhesion molecule 1, monocyte chemotactic protein 1, and interleukin-1. Consistently, TET2 knockdown with small hairpin RNA (shRNA) in $\mathrm{ApoE}^{-/-}$mice decreased $5 \mathrm{hmC}$ and increased $5 \mathrm{mC}$ levels in atherosclerotic lesions. Meanwhile, autophagy was inhibited and atherosclerotic lesions progressed with an unstable lesion phenotype characterized by large lipid core, macrophage accumulation, and upregulated inflammation factor expression. Experiments with the cultured endothelial cells revealed that oxidized low-density lipoprotein (ox-LDL) inhibited endothelial cell autophagy. TET2 shRNA strengthened impaired autophagy and autophagic flux in the ox-LDL-treated endothelial cells. TET2 overexpression reversed these effects by decreasing the methylation level of the Beclin 1 promoter, which contributed to the downregulation of inflammation factors. Overall, we identified that TET2 was downregulated during the pathogenesis of atherosclerosis. The downregulation of TET2 promotes the methylation of the Beclin 1 promoter, leading to endothelial cell autophagy, impaired autophagic flux, and inflammatory factor upregulation. Upregulation of TET2 may be a novel therapeutic strategy for treating atherosclerosis.

\section{INTRODUCTION}

Atherosclerosis, a complex disease that involves chronic inflammation and vascular remodeling processes, is the leading cause of death and morbidity among adults in developed countries. Recently, increasing evidence has indicated that autophagy is impaired during atherosclerotic plaque development and contributes to lipid metabolism 
dysfunction and vascular endothelial cell (EC) dysfunction [1-3].

Autophagy is a dynamic process of recycling in which cells degrade malfunctioning or damaged proteins and organelles within their lysosomes; this process plays a crucial role in cellular homeostasis. DNA methylation of some key autophagy-related (ATG) genes regulates autophagy. LC3I, an important positive regulator of autophagy, is frequently methylated in esophageal squamous-cell carcinoma [4]. Autophagy-related protein Beclin 1 promoter displays aberrant methylation, and its expression is significantly downregulated in breast tumors $[5]$.

Methylation of cytosine at $\mathrm{CpG}$ sequences of the promoter is an epigenetic modification linked to gene expression regulation. Alterations in DNA methylation profiles are early markers of atherosclerosis in $\mathrm{ApoE}^{-/}$ mice, and atherogenic lipoproteins induce DNA hypermethylation in cultured cells [6]. 5-Methylcytosine $(5 \mathrm{mC})$ is elevated in the intima of $\mathrm{ApoE}^{-/-}$mice fed a highfat diet (HFD), and high $5 \mathrm{mC}$ levels are linked to lowdensity lipoprotein (LDL) receptor and p53 mutation in vascular cells. Inhibition of DNA methylation by 5-Aza2'-deoxycytidine (5Aza) or DNA methyltransferase by siRNA obviously inhibits endothelial inflammation and lesion formation [7]. This finding suggests that the balance between DNA methylation and demethylation is disrupted during atherosclerosis and that DNA methylation is predisposed to the pathogenesis of atherosclerosis.

Tet methylcytosine dioxygenase 2 (TET2), a member of the Ten-eleven translocation (TET) enzyme family, converts $5 \mathrm{mC}$ to $5 \mathrm{hmC}$ and modifies DNA methylation status $[8,9]$. The loss of TET2 is associated with an increased hematopoietic stem cell self-renewal and skewed differentiation favoring monocytic lineage [10-12]. TET2 $^{-/-}$mice are prone to develop myeloid malignancies, including chronic myelomonocytic leukemia and myeloproliferative neoplasm-like myeloid leukemia. Moreover, TET2's loss of production of $5 \mathrm{hmC}$ is a novel epigenetic hallmark for melanoma. Recently, Liu et al. [13] have shown that TET2 is associated with atherosclerosis via a master epigenetic regulator of smooth muscle cell differentiation. Our previous study showed that the inhibition of TET2 expression in oxidized-LDL (ox-LDL)-treated macrophages contributes to autophagy impairment and lipid accumulation in macrophages [14]. Meanwhile, the inhibition of TET2 expression in vascular ECs under low shear stress promotes autophagy impairment in ECs and EC dysfunction via the upregulation of endothelial nitric oxide synthase and the downregulation of endothelin-1 [15]. However, whether TET2 dysregulation is directly implicated in the initiation and progression of atherosclerosis remains to be determined.

In the present study, we investigated the role of TET2 in atherosclerosis and its potential mechanisms.
Results showed that the levels of TET2 and its product $5 \mathrm{hmC}$ decreased in atherosclerotic lesions. The downregulation of TET2 increased atherosclerotic lesions with increased macrophage accumulation and inflammatory factor expression in HFD-fed $\mathrm{ApoE}^{-/-}$ mice. Mechanistically, TET2 promoted autophagic flux in endothelial cells by increasing Beclin 1 promoter demethylation.

\section{RESULTS}

\section{TET2 and $5 \mathrm{hmC}$ are decreased and $5 \mathrm{mC}$ is increased in atherosclerotic lesions in $\mathrm{ApoE}^{-1-}$ mice}

To determine the role of TET2 in atherosclerosis, we first analyzed the extent of TET2 in normal vascular tissue and atherosclerotic lesions in $\mathrm{ApoE}^{-/-}$mice. TET2 expression was homogeneously present across the vascular wall in atherosclerosis-free arteries. TET2 expression was barely detected in the intima of atherosclerotic lesions but was abundant in the shoulder regions. In addition, the production of $5 \mathrm{hmC}$ decreased while that of its substrate $5 \mathrm{mC}$ increased in atherosclerotic lesions compared with the corresponding normal vascular tissue (Figure 1). Overall, these data suggest that TET2 downregulation contributes to the formation and progression of atherosclerotic plaques.

\section{TET2 significantly reduces the formation of atherosclerotic lesions in $\mathrm{ApoE}^{-/-}$mice}

We further explored the effects of TET2 intervention (TET2 overexpression or TET2 small hairpin RNA [shRNA]) on atherosclerotic lesions in HFD-fed ApoE ${ }^{-/-}$ mice. We examined the levels of TET2, $5 \mathrm{mC}$, and $5 \mathrm{hmC}$ in atherosclerotic lesions in mice from each group. As anticipated, TET2 overexpression positively correlated with $5 \mathrm{hmC}$ and negatively correlated with $5 \mathrm{mC}$ levels. Treatment with TET2 shRNA decreased 5 hmC level but increased $5 \mathrm{mC}$ level in $\mathrm{ApoE}^{-/}$mice (Supplementary Figure 1).

No difference in body weight, total cholesterol, triglyceride, HDL and LDL levels was found among the mice in the three groups (Supplementary Figure 2). En face preparations of the total aorta (Figure 2A) showed less plaque in the TET2 overexpression group and more plaque in the TET2 shRNA group compared with the control mice. The plaque area in the proximal aorta was extensively examined in the Oil-red-stained cross-sections of the aortic root. We observed that TET2 overexpression significantly decreased atherosclerotic lesions, but treatment with TET2 shRNA significantly increased the 


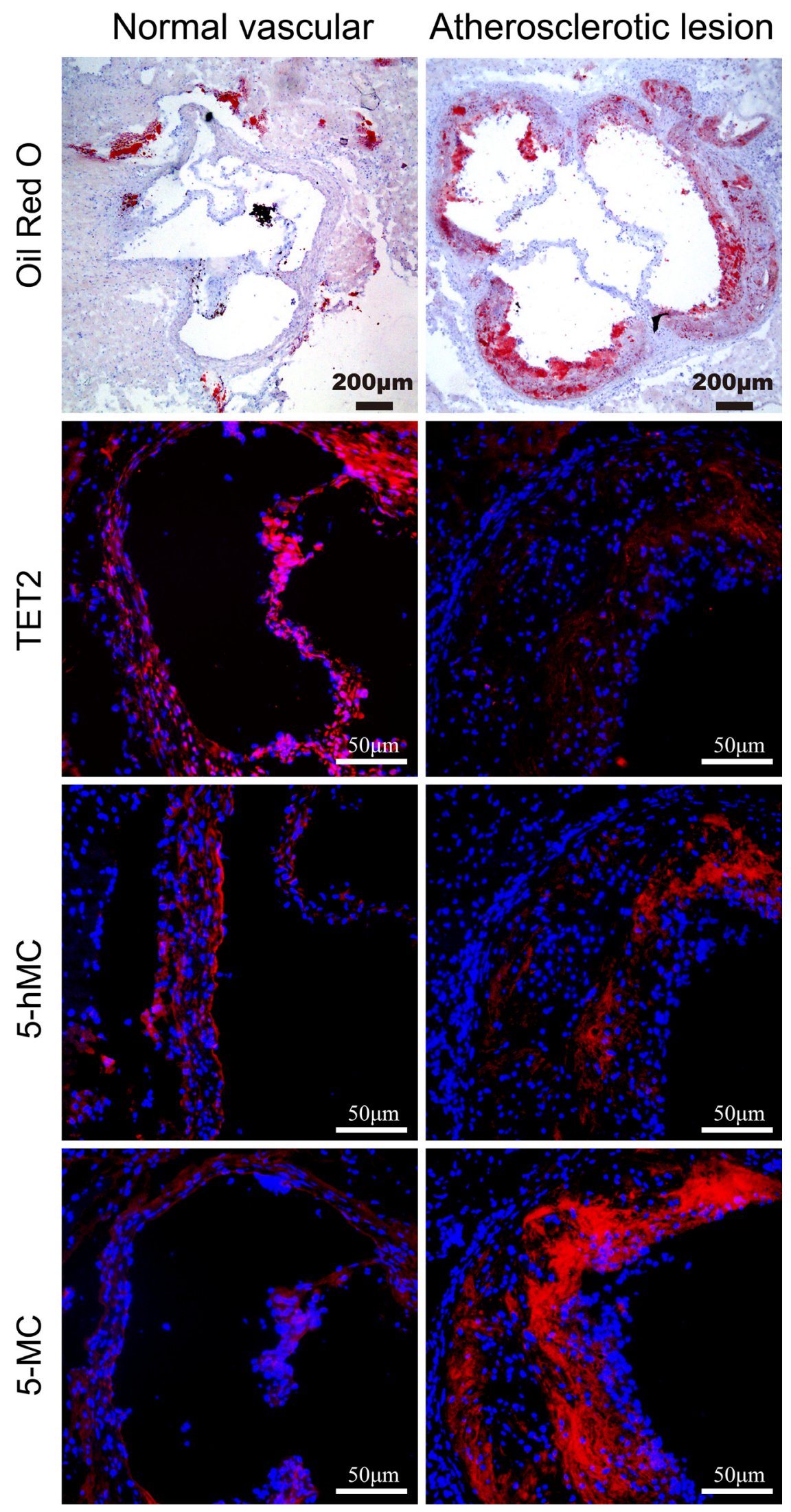

Figure 1: Distribution of TET2, $5 \mathrm{hmC}$, and $5 \mathrm{mC}$ in atherosclerotic lesions and normal vascular tissue. Immunostaining was performed using antibodies against TET2, $5 \mathrm{hmC}$, and $5 \mathrm{mC}$ in normal vascular and atherosclerotic tissues in ApoE- $/^{-}$mice $(n=10$ each). Cell nuclei were counterstained with DAPI. Scale bars are 200 and $50 \mu \mathrm{m}$. 
A

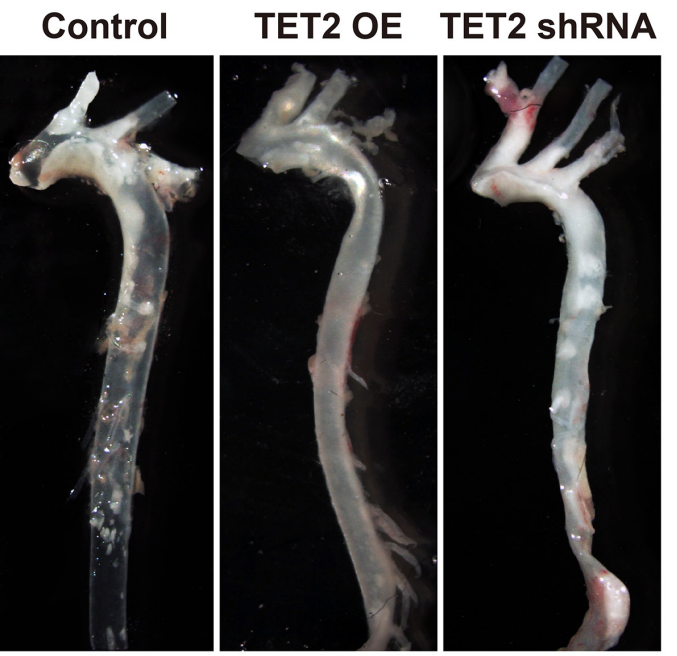

C

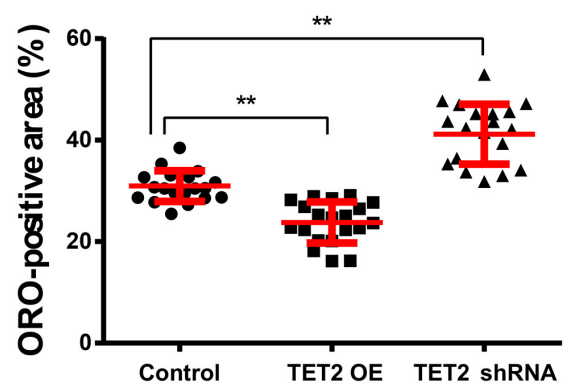

B

Control

TET2 OE

TET2 shRNA

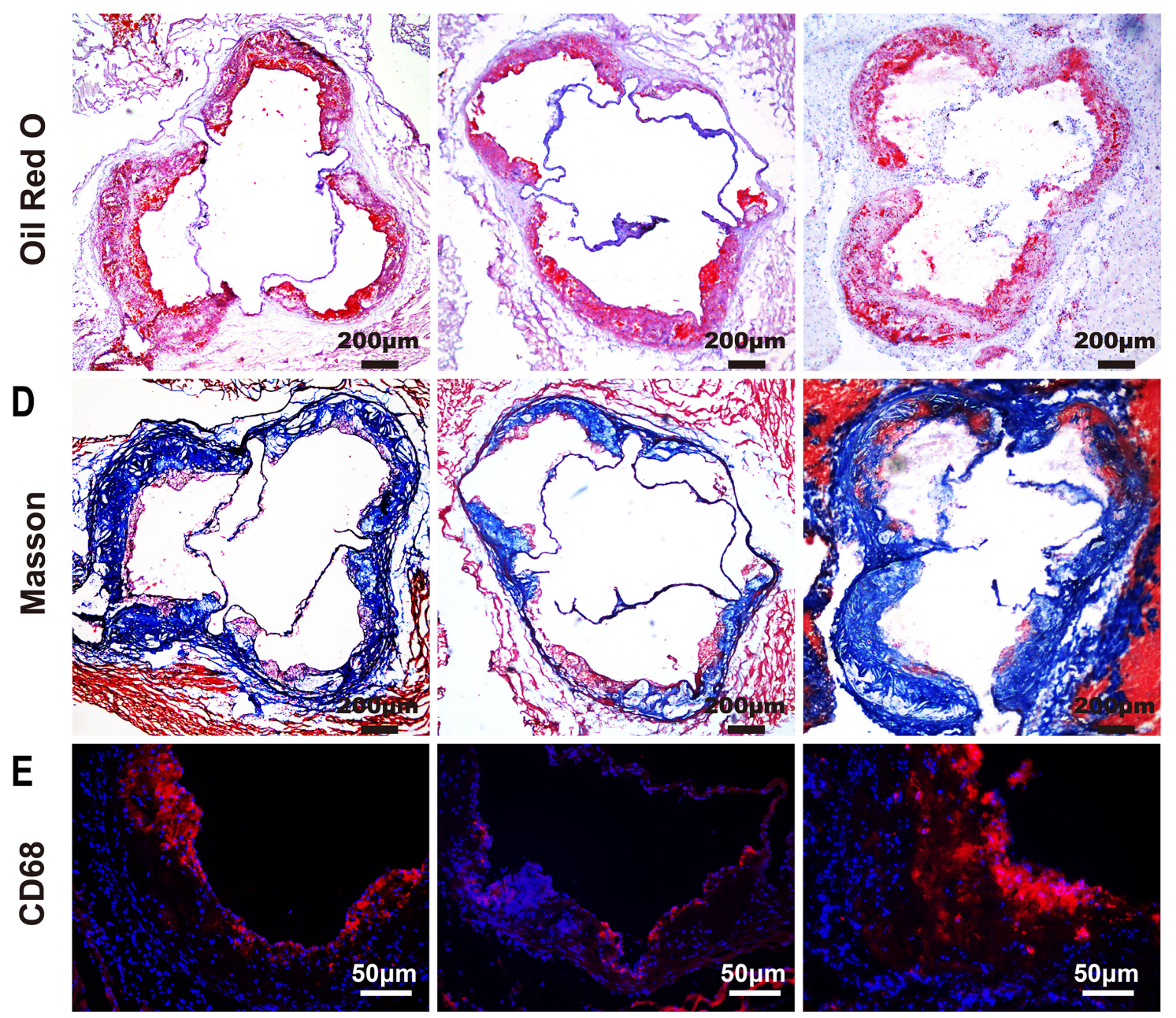

Figure 2: TET2 inhibited the atherosclerotic lesion progression of high fat-fed $\mathbf{A p o E}^{-/-}$mice. A. Representative en face preparations of the total aorta in ApoE-/- mice treated with TET2 overexpression or TET2 shRNA lentiviruses fed a high-fat diet for 12 weeks. B.-C. Representative microscopic images and quantification of atherosclerotic plaque areas in cross-sections of aortic roots with Oil-red staining in ApoE- $/^{-}$mice treated with TET2 overexpression or TET2 shRNA lentiviruses fed a high-fat diet for 12 weeks. Values are mean $\pm \operatorname{SEM}(n=20$ each $)$. D.-E. Representative microscopic images of the aortic sinus with Masson's Trichrome staining and immunostaining for CD68 (a macrophage marker) in ApoE-/- mice treated with TET2 overexpression or TET2 shRNA lentiviruses fed a high-fat diet for 12 weeks. ${ }^{* * P}<0.01$ compared with the control group. TET2 OE:TET2 overexpression. 
lesions in the aortic root compared with those in control mice (Figures 2B and 2C). A more random orientation and less organized structure of lesional collagen fibrils were also observed in the TET2 shRNA-treated group than in the control group (Figure 2D). Meanwhile, the accumulation of CD68-positive macrophages decreased in the TET 2 overexpression group but significantly increased in the TET2 shRNA-treated group (Figure 2E).
TET2 reduces the expression of pro-inflammatory cytokines in plaques

Atherosclerosis is a long-term chronic inflammatory process associated with inflammatory cells, adhesion molecules, inflammatory cytokines, and chemokines. Adhesion molecules, such as intercellular adhesion molecule 1 (ICAM-1) and vascular cell adhesion molecule 1 (VCAM-1), promote plaque instability, weaken the

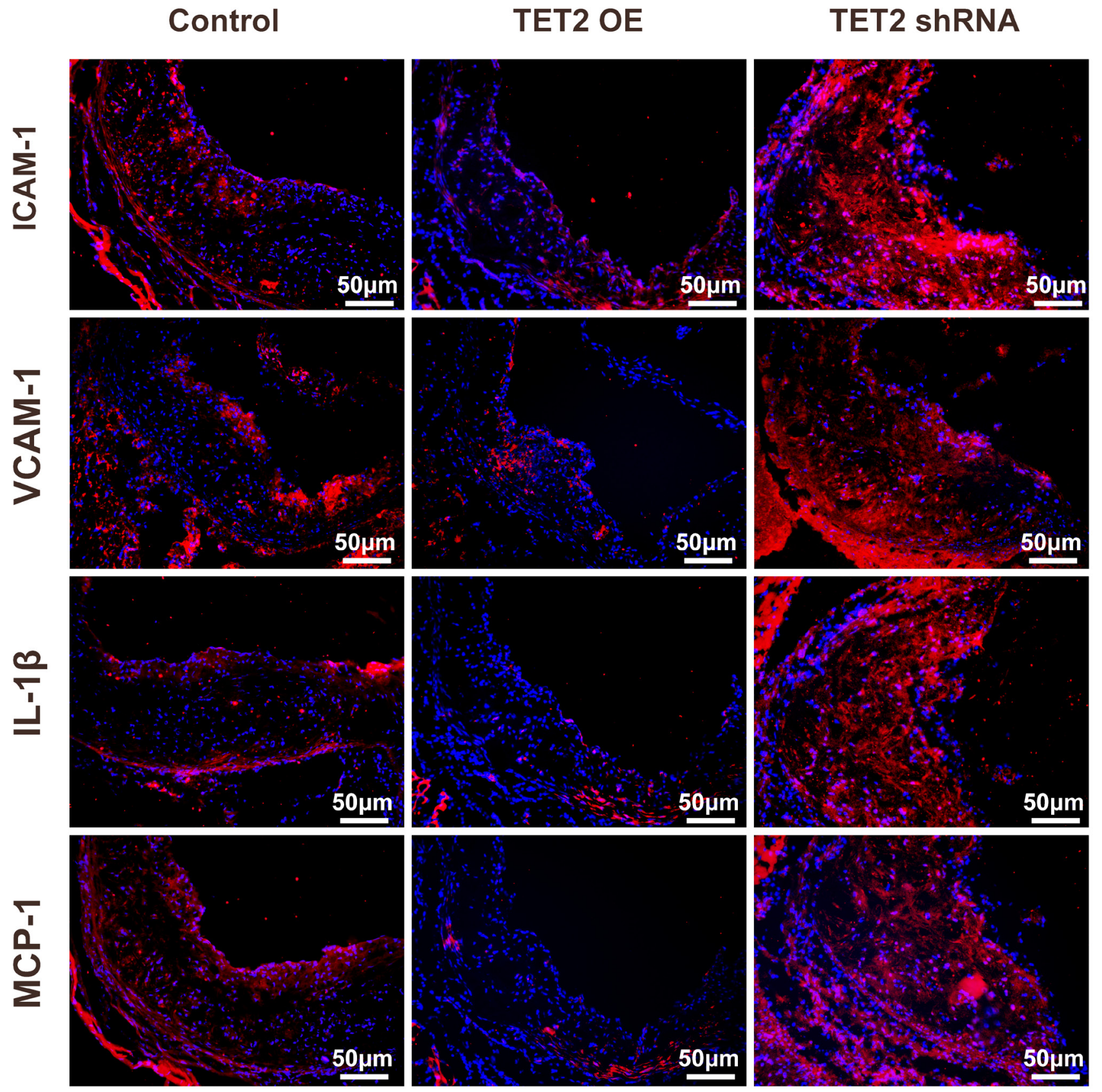

Figure 3: TET2 inhibited inflammation factor expression in the atherosclerotic lesions of high fat-fed ApoE ${ }^{-/-}$mice. Representative micrographs of immunofluorescence staining of ICAM-1, VCAM-1, IL-1 $\beta$, and MCP-1 in atherosclerotic plaques were derived from the control, TET2 OE, and TET2 shRNA ApoE ${ }^{-/-}$mice fed with a high-fat diet for 12 weeks $(n=10$ each). Scale bar is 50 $\mu \mathrm{M}$. TET2 OE:TET2 overexpression. 
plaque fibrous cap, and accelerate plaque rupture and thrombosis. As shown in Figure 3, ICAM-1, VCAM-1, interleukine-1 beta (IL-1 $\beta$ ) and monocyte chemotactic protein 1 (MCP-1) were abundantly expressed in atherosclerotic lesions as previously reported [16, 17]. The TET2 overexpression group showed significantly less positive staining areas for ICAM-1, VCAM-1, IL-1 $\beta$, and MCP-1 than the control group. In addition, the TET2 shRNA group had a significant increase in the expression of these inflammation factors.

\section{Expression of TET2 is involved in the regulation of vascular cell autophagy in $\mathrm{ApoE}^{-/-}$mice}

Autophagy, a compensatory mechanism to maintain cell homeostasis, has recently been implicated as a protective mechanism during atherosclerosis [18] In the present study, the autophagy markers Beclin 1, LC3, and p62 were examined in TET2-overexpressing and TET2 shRNA-treated $\mathrm{ApoE}^{-/-}$mice.

Beclin 1 is a key regulator of autophagosome formation during autophagy. p62 is a ubiquitin-binding protein that interacts with $\mathrm{LC} 3$ to mediate the degradation of polyubiquitinated protein aggregates and mitochondria via the autophagy-lysosome pathway. The accumulation of p62 indicates defective autophagy lysosomes. The plaques and aortic archs in the TET2-overexpressing $\mathrm{ApoE}^{-/-}$ mice were characterized by an increased expression of Beclin 1 and LC3 and a decreased accumulation of p62 as compared with those in the control $\mathrm{ApoE}^{-/-}$mice (Figure 4). Consistent with these results, the expression of Beclin 1 and LC3 decreased and the accumulation of p62 increased in the TET2 shRNA-treated ApoE ${ }^{-/-}$mice (Figure 4). These data suggest that TET2 is involved in vascular cell autophagy and that the loss of TET2 contributes to autophagy impairment during the progression of atherosclerosis.

\section{TET2 increases $5 \mathrm{hmC}$ and decreases $5 \mathrm{mC}$ in ox-LDL-treated human umbilical vascular endothelial cell lines (HUVECs)}

Ox-LDL-induced endothelium dysfunction initiates atherosclerotic lesion formation and progression. TET2 overexpression significantly increased $5 \mathrm{hmC}$ level but significantly decreased $5 \mathrm{mC}$ level in ox-LDL-treated HUVECs. This finding was further confirmed when the increased level of $5 \mathrm{hmC}$ and the decreased level of $5 \mathrm{mC}$ were inhibited by treatment with TET2 shRNA (Figure 5).

\section{TET2 improves autophagy and autophagic flux in} ox-LDL-treated HUVECs

Oxidized lipoproteins lead to endothelial cell dysfunction by altering autophagy [19]. To determine the potential involvement of autophagy and autophagic flux in the effects of TET2 on ox-LDL-treated endothelial cells, we pretreated HUVECs with either TET2 overexpression or TET2 shRNA, followed by treatment with $50 \mathrm{mg} / \mathrm{L}$ ox-LDL for $24 \mathrm{~h}$. As shown in Figures 6A and 6B, TET2 overexpression increased the levels of Beclin 1 and LC3II protein, but treatment with TET2 shRNA elicited the opposite effect. Meanwhile, p62 expression was decreased by TET 2 overexpression and increased by treatment with TET2 shRNA, suggesting that TET2 regulates the autophagy of endothelial cells in the presence of ox-LDL treatment. The protective effect of autophagy requires autophagic flux through lysosomes [20]. Therefore, we used the tandem GFP-RFP-LC3 adenovirus to confirm the role of TET2 in the autophagy flux of endothelial cells. As shown in Figure 5C, TET2 overexpression resulted in more red puncta and less green puncta in endothelial cells compared with control cells, indicating that TET2 induced autolysosome formation. These results suggest that TET2 promotes autophagy flux in ox-LDL-treated HUVECs.

To elucidate the potential mechanisms underlying the effects of TET2 on autophagy in endothelial cells, we analyzed the methylation of the Beclin 1 promoter. Bioinformatic analysis showed two $\mathrm{CpG}$ islands (662-774 bp and 829-1225 bp) containing 14 and $21 \mathrm{CpG}$ sites in the Beclin 1 promoter, respectively. Sequence analysis revealed that TET2 overexpression significantly decreased the average methylation rate of the first $\mathrm{CpG}$ island but not that of the second one (Figure 6D).

\section{TET2 inhibits inflammatory factor expression in ox-LDL-treated HUVECs}

Atherosclerosis is characterized by impaired autophagy, and autophagy deficiency promotes atherosclerosis in part by activating the inflammasome [21]. We assessed the effects of TET2 on the expression of inflammatory factors in ox-LDL-induced HUVECs. The expression of ICAM-1, VCAM-1, IL-1 $\beta$, and MCP1 was significantly attenuated in response to TET2 overexpression and further increased by TET2 shRNA in ox-LDL-treated HUVECs (Figure 7).

\section{DISCUSSION}

In this study, TET2 and its production decreased in atherosclerotic lesions. The overexpression of TET2 significantly downregulated the expression of inflammatory factors and the accumulation of macrophages in atherosclerotic lesions. This phenomenon resulted in the 

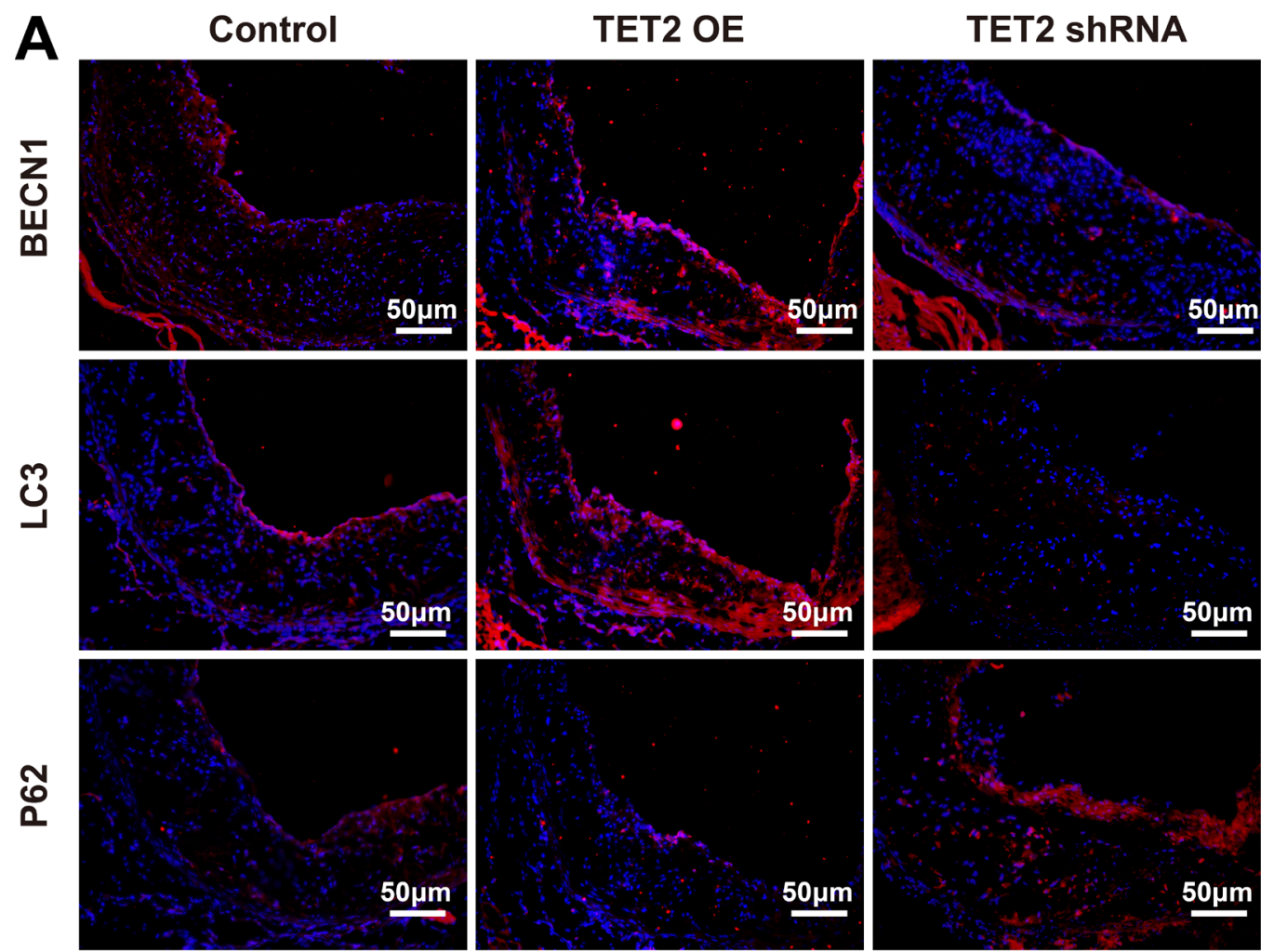

B
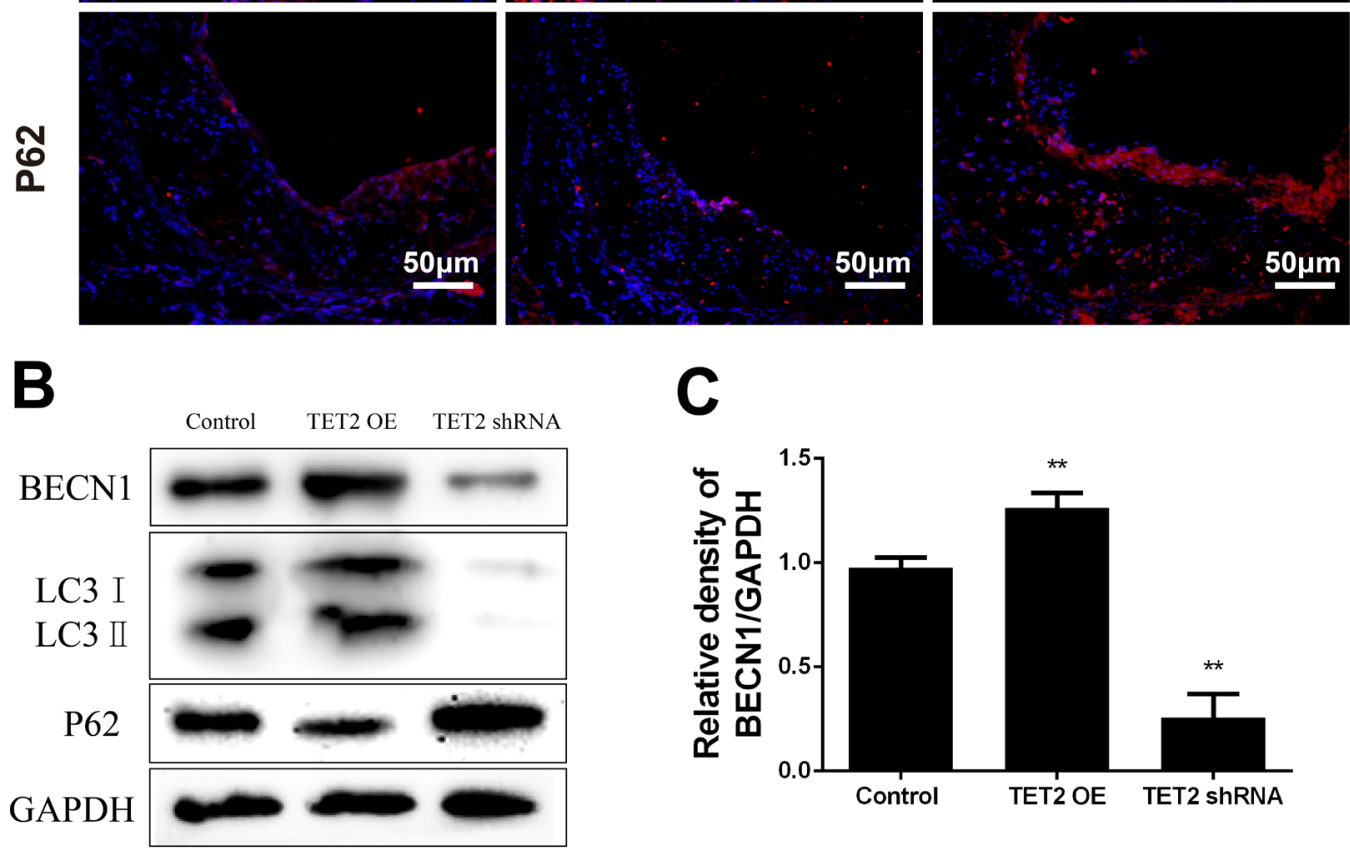

D

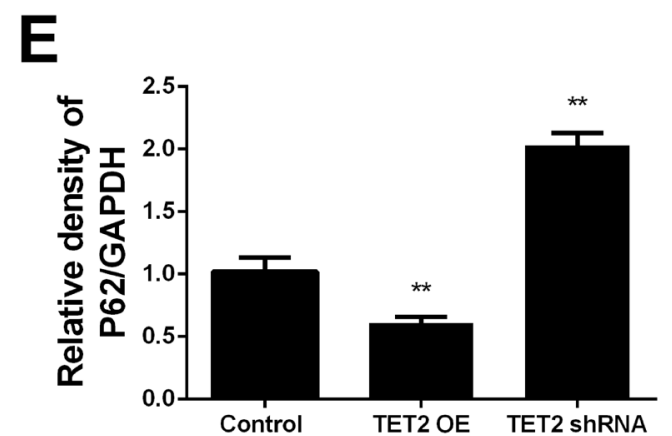

Figure 4: TET2 improved autophagy in the atherosclerotic lesions of high-fat-fed $\mathbf{A p o E}^{-/}$mice. A. Representative micrographs of immunofluorescence staining of autophagy markers, such as Beclin 1, LC3, and p62, in atherosclerotic plaques were derived from the control, TET2 OE, and TET2 shRNA ApoE ${ }^{-/-}$mice fed with high-fat diets for 12 weeks. DAPI was used for nuclear stains (blue). Scale bar is $50 \mu \mathrm{M}$. B. Representative Western blots showing the levels of Beclin 1, LC3, and p62 in aortic arch in the different groups. C.-E. Quantitative data showing the levels of autophagy-related proteins in aortic arch in the different groups. All results are expressed as mean \pm S.D. $(n=3$ each). $* P<0.05, * * P<0.01$ versus control group. TET2 OE:TET2 overexpression. 

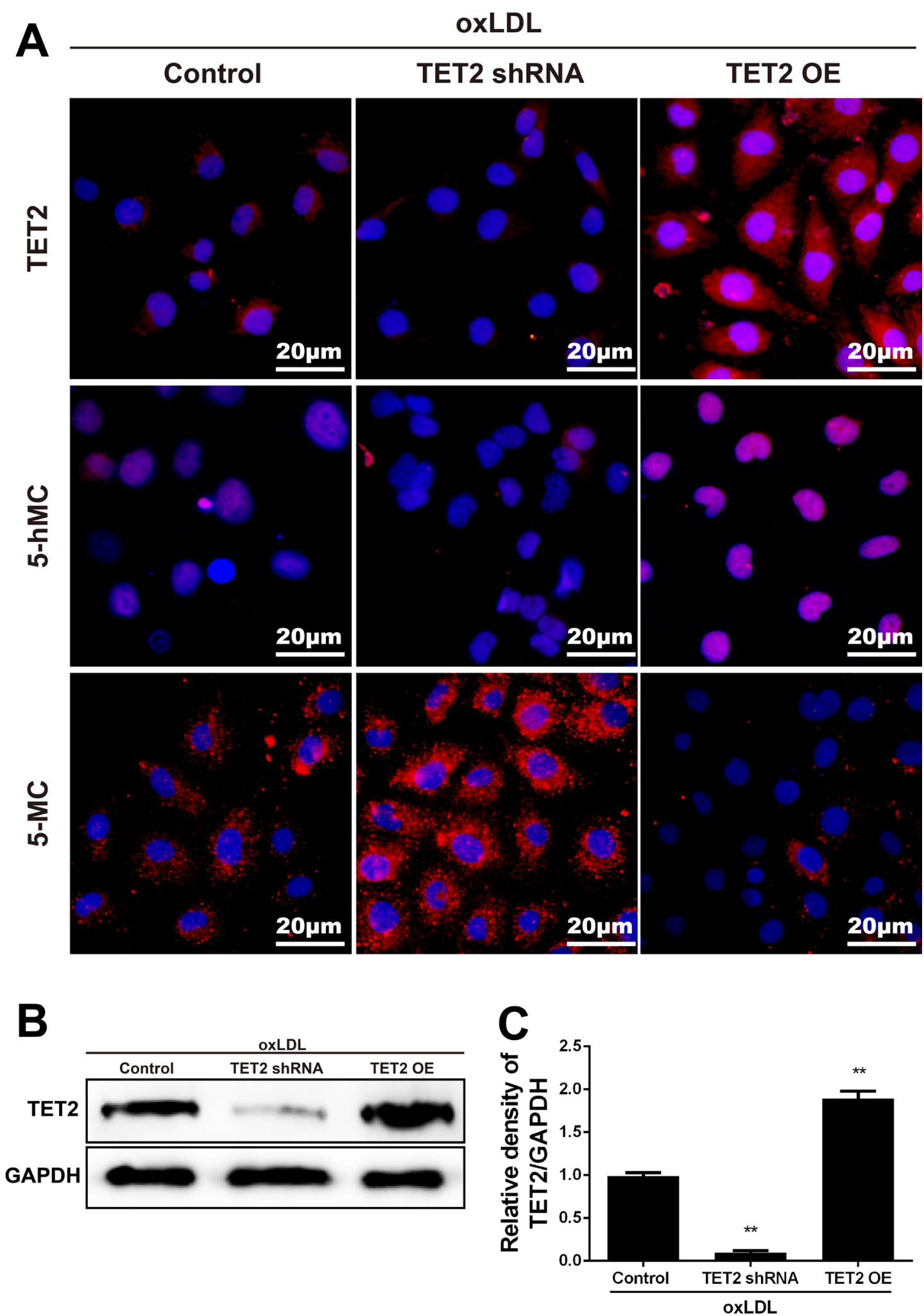

Figure 5: TET2 increased 5hmC level and decreased $5 \mathrm{mC}$ level in ox-LDL-treated HUVECs. A. Representative immunostaining micrographs show that TET2 OE enhanced $5 \mathrm{hmC}$ level and reduced $5 \mathrm{mC}$ level in HUVECs treated with $50 \mathrm{mg} / \mathrm{L}$ oxLDL for $24 \mathrm{~h}$. Consistently, treatment with TET2 shRNA reduced $5 \mathrm{hmC}$ generation and increased $5 \mathrm{mC}$ generation. DAPI was used for nuclear staining (blue). Scale bar is $20 \mu \mathrm{M}$. B.-C. TET2 levels were determined in HUVECs with different treatments using Western blot. Values are mean \pm SD from three independent experiments, each performed in triplicate. ${ }^{*} P<0.01$ versus control group. TET2 OE:TET2 overexpression.TET2 OE:TET2 overexpression. 
significant reduction of atherosclerosis. TET2 regulated autophagy and autophagic flux by modifying Beclin 1 promoter methylation in vascular endothelial cells. These data indicate that TET2 plays a unique role in the pathophysiological process of atherosclerosis.

TET2 participates in DNA methylation regulation by mediating oxidation in the conversion of $5 \mathrm{mC}$ to $5 \mathrm{hmC}$, which epigenetically regulates gene expression by altering methylation-driven gene silencing. TET $2^{-/-}$mice show a dramatic reduction in $5 \mathrm{hmC}$ level and a concomitant increase in $5 \mathrm{mC}$ level in the genomic DNA of bone marrow cells [22]. The loss of TET2 and its production of $5 \mathrm{hmC}$ are closely associated with diverse types of cancers, such as myeloid leukemia, melanoma, and colorectal,
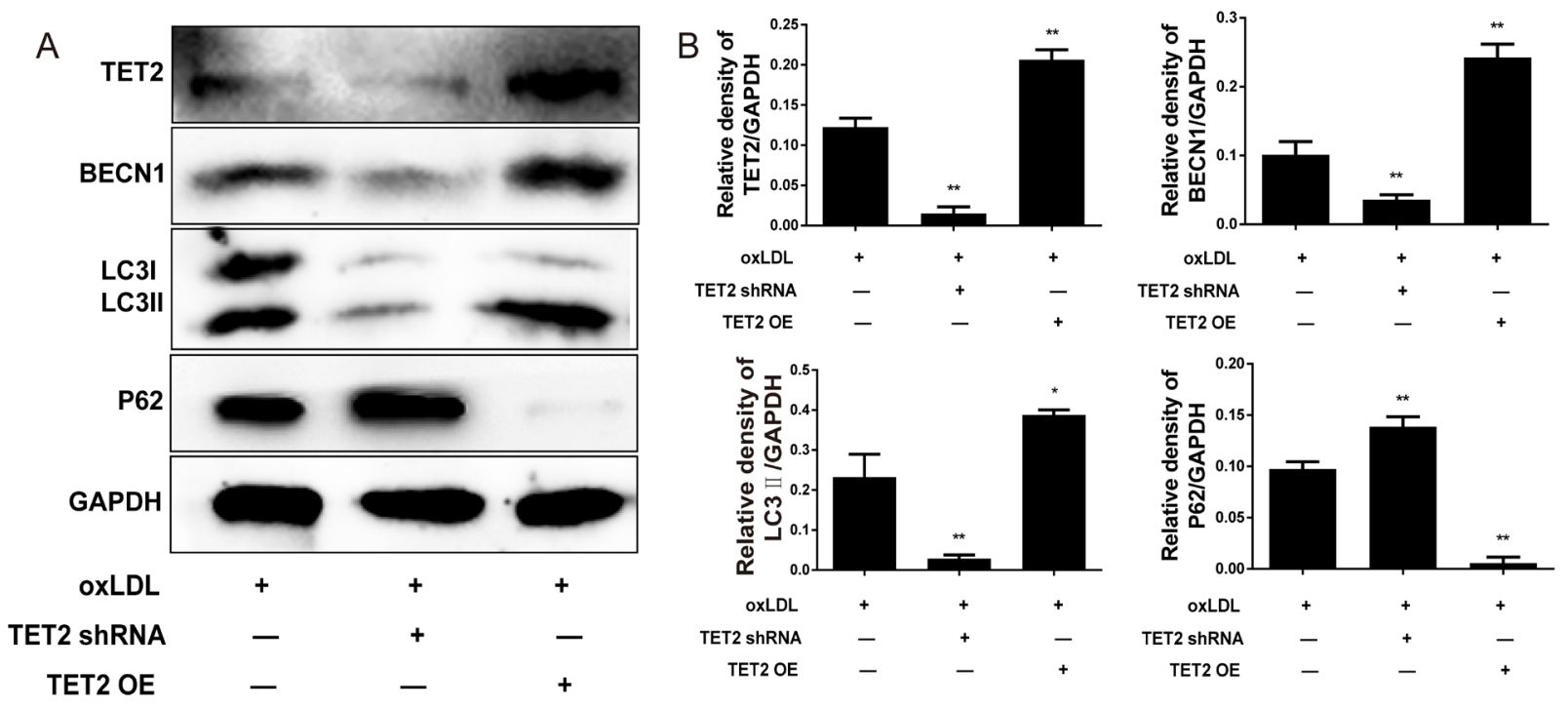

C

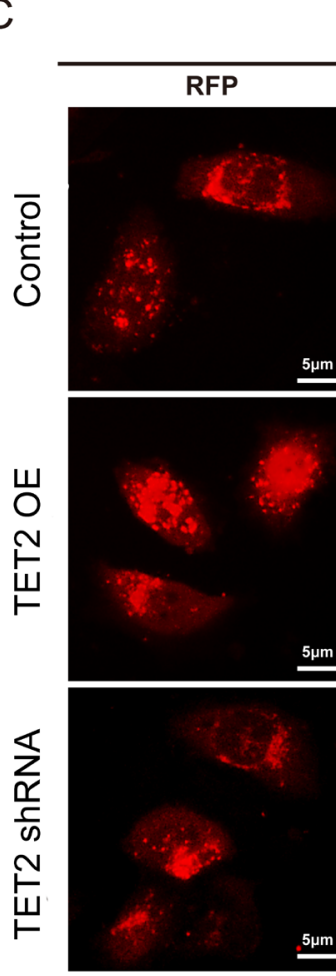

GFP-RFP-LC3
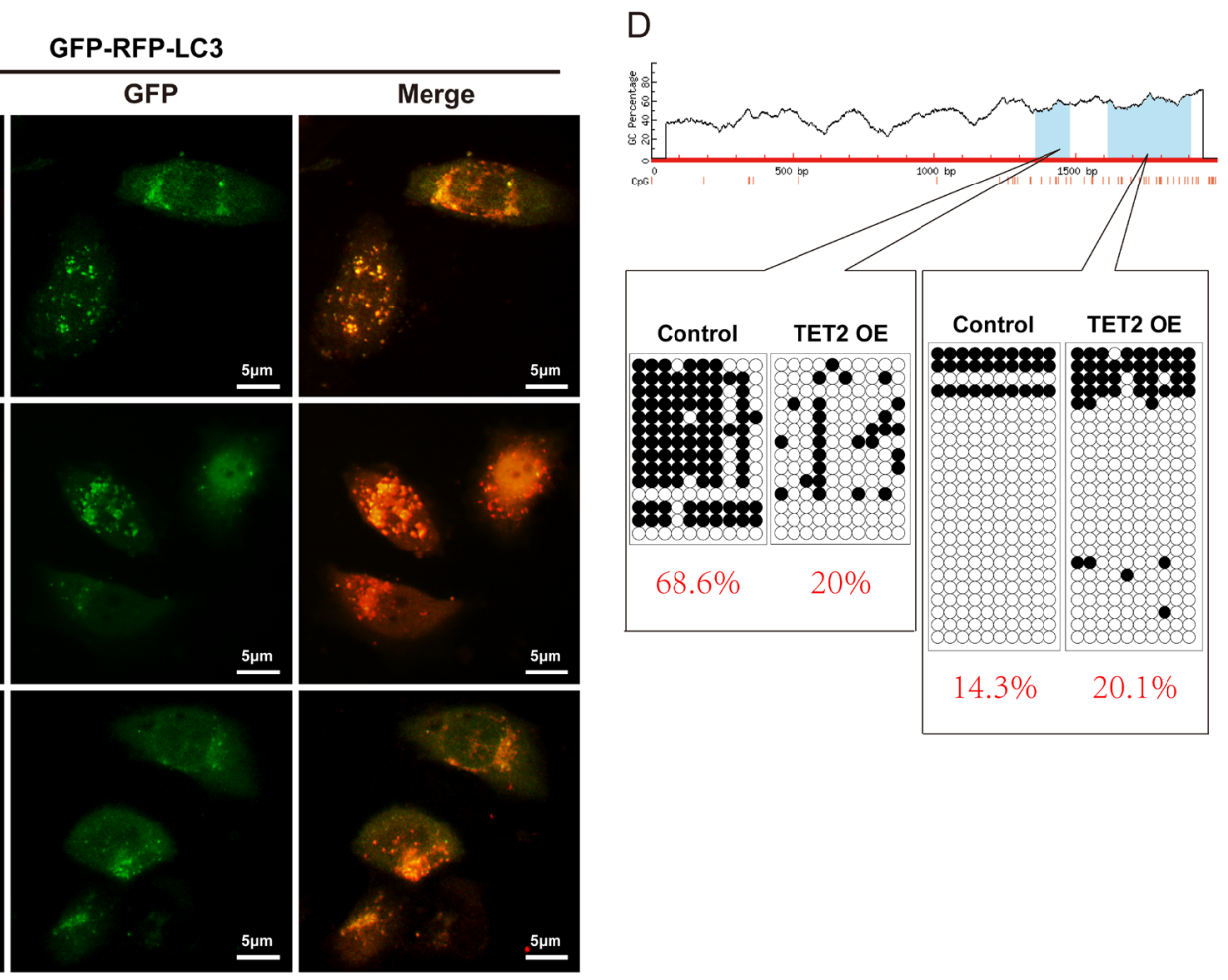

Figure 6: TET2 improved autophagy and autophagic flux in ox-LDL-treated HUVECs. A. Representative Western blots showing the levels of Beclin 1, LC3 and p62 in HUVECs with different treatments. B. Quantitative data showing the levels of autophagyrelated proteins in HUVECs with different treatments. All results are expressed as mean \pm SD from three independent experiments, each performed in triplicate. ${ }^{*} P<0.05,{ }^{*} P<0.01$ versus ox-LDL-treated group. C. Representative images showing LC3 localization in HUVECs from different groups infected with the GFP-RFP-LC3 adenovirus for $24 \mathrm{~h}$. Scale bar is $5 \mu \mathrm{M}$. D. Bisulfite sequence analysis was performed to compare the DNA methylation at the Beclin 1 promoter. 
OXLDL

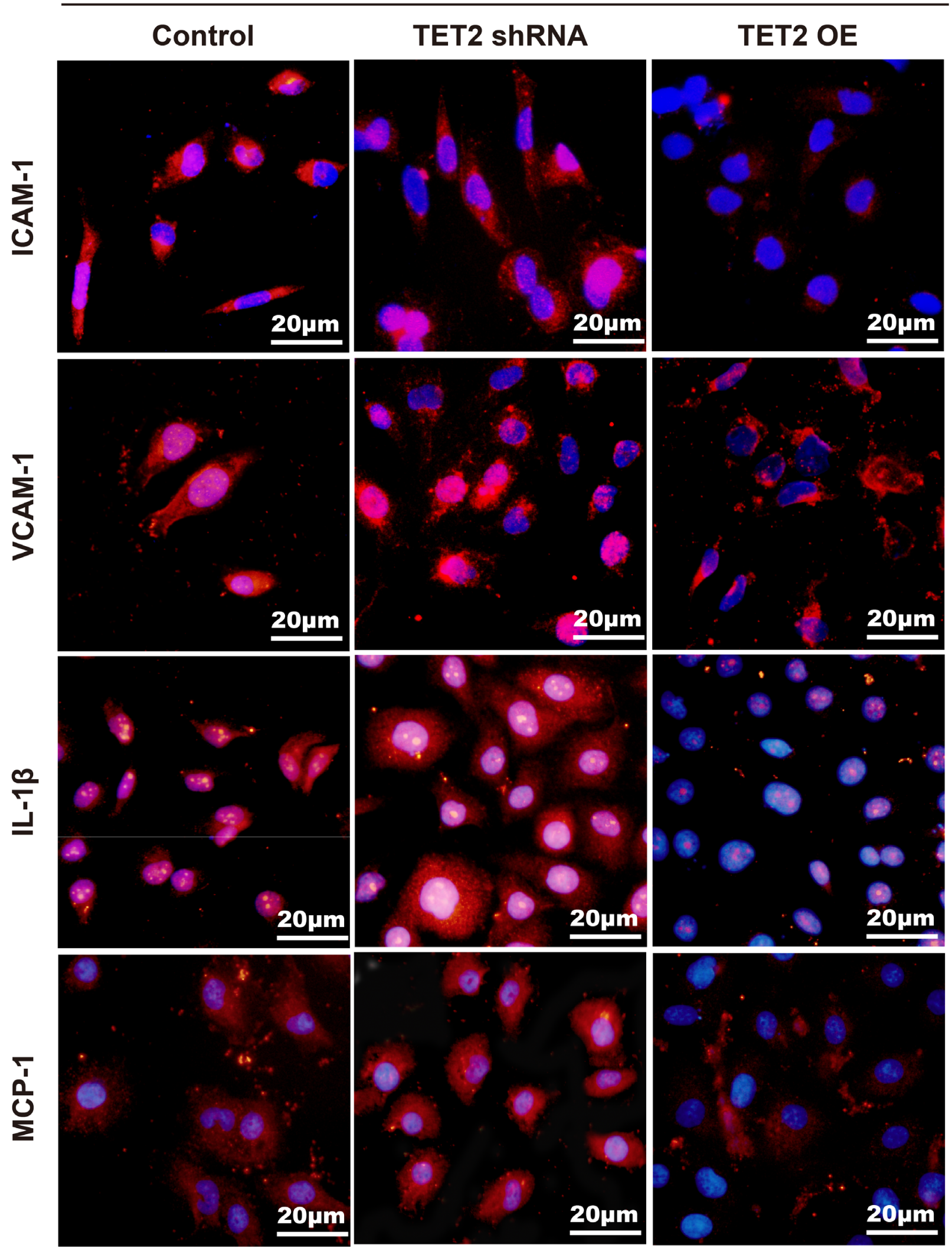

Figure 7: TET2 inhibited the expression of inflammatory factors in ox-LDL-treated HUVECs. The increased levels of VCAM-1, ICAM-1, IL-1 $\beta$, and MCP-1 in response to ox-LDL treatment were reduced by TET2 OE and further elevated by TET2 shRNA. Scale bar is $20 \mu \mathrm{M}$. 
breast, liver, and lung cancers. In the present study, the expression levels of TET2 and $5 \mathrm{hmC}$ obviously decreased in atherosclerotic lesions. Furthermore, TET2 contributed to the promoter methylation status of Beclin 1, a key regulator of autophagy that governs the autophagic process by regulating the generation of phosphatidylinositol3phosphate and the subsequent recruitment of additional Atg proteins that orchestrate autophagosome formation [23]. Consistent with this finding, autophagy and autophagic flux in ox-LDL-treated endothelial cells were improved by TET 2 overexpression and further impaired by TET 2 shRNA. The vascular cell autophagy was also upregulated in ApoE-/- mice with TET2 overexpression and was decreased in ApoE-/- mice treated with TET2 shRNA. Overall, these observations suggest that TET2 is an important regulator in autophagy and autophagic flux in endothelial cells.

Inflammatory processes play a crucial role in all stages of atherosclerosis. In the early stage of atherosclerosis, entrapped ox-LDL in the vessel wall activates arterial endothelial cells and also recruits monocytes and $\mathrm{T}$ cells. Upon recruitment, monocytes can differentiate into macrophages. Autophagy acts as a negative regulator of inflammation. ATG16 $\mathrm{L}^{-/-}$mice show high IL- $1 \beta$ and IL-18 levels in sera in response to LPS stimulation or during colitis [24]. The detailed molecular mechanisms by which autophagy regulates inflammation are not yet fully understood. In general, autophagy protects cells from excessive long-lasting inflammation in an indirect manner by allowing efficient clearance of damaged organelles (e.g., mitochondria,) and/or in a direct manner by suppressing proinflammatory complexes (e.g., mitochondrial ROS and DNA) [25, 26]. Autophagy impairment, which occurs in atherosclerotic lesions, promotes atherosclerosis at least partially by upregulating inflammation [27]. TET2 overexpression decreased the expression of inflammatory mediators, such as VCAM1, ICAM-1, IL-1 $\beta$, and MCP-1, in cultured endothelial cells. VCAM-1 and ICAM-1 are the major cytokines in monocyte adhesion that triggers the transformation from monocytes to macrophages within the vascular wall. MCP-1 is related to leukocyte recruitment, and IL-1 $\beta$ contributes to monocyte/macrophage differentiation. Consistently, the accumulation of macrophages within the lesions in HFD-fed ApoE-/- mice was significantly attenuated in response to TET2 overexpression. This role of TET 2 was further confirmed by TET 2 shRNA. The increased accumulation of macrophages is associated with an increased incidence of plaque rupture with subsequent thromboembolism, leading to ischemic neurological and cardiovascular events. Therefore, the loss of TET2 might result in vulnerable plaque formation, and TET2 upregulation may be beneficial to prevent atherosclerosis.

Ichiyama et al. [28, 29] showed that TET2 upregulates the expression of IL-10 and IL-17 by promoting DNA demethylation and repressing IL-6 expression through the recruitment of Hdac2 to IL-6 promoter. Therefore, TET2 might protect cells from inflammation by improving autophagy and direct antiinflammation effect, suggesting that TET2 overexpression is an attractive strategy to treat atherosclerosis. Other experiments are required to elucidate the exact molecular mechanisms underlying TET2 effects and its roles in signal transduction pathways, which will be clinically targeted for the prevention or treatment of atherosclerosis.

\section{MATERIALS AND METHODS}

\section{Animals}

ApoE $-{ }^{-}$mice (male, 8 weeks old) were purchased from the Department of Laboratory Animal Science, Peking University Health Science Center, China. All mice were housed in a specific pathogen-free environment throughout the experiment and fed HFD (20\% fat and $0.15 \%$ cholesterol; Qingzilan, Jiangsu, China) for 12 weeks. Mice were weighed before and after the HFD feeding. All animals in this study were housed in accordance with the guidelines of the Institutional Animal Care and Use Committee of the University of South China. All experimental procedures were approved by the Department of Medical Ethics at the University of South China.

\section{Lentivirus transduction}

The lentiviruses containing shRNAs (sense-loopantisense) for mouse TET2 or the TET2-expression vectors were purchased from GeneChem Corporation (Shanghai, China). Infection of ApoE-/- mice by lentivirus was performed by intravenous tail vein injection.

\section{Quantification of atherosclerosis lesions}

Mouse hearts and whole aortas were removed and embedded in OCT, and $8 \mu \mathrm{m}$ serial sections of the aortic root were cut for analysis of lesion morphologies with Oil Red O staining, Masson trichrome staining. The extent of the atherosclerotic lesions of each animal was calculated as the mean lesion area of five sections. Histological sections were quantified by the computer-assisted morphometric analysis using ImageJ software (National Institutes of Health, Bethesda, MD). Data were expressed as lesion size \pm SEM.

\section{Plasma lipid analysis}

Mice were fasted for $6 \mathrm{~h}$ prior to sacrifice. Blood samples were drawn by cardiac puncture using a $25 \mathrm{G}$ 
needle mounted on a $1 \mathrm{~mL}$ syringe and then collected in an EDTA-containing tube. Plasma was separated by centrifugation at $2000 \times g$ for $10 \mathrm{~min}$ and then stored at 4 ${ }^{\circ} \mathrm{C}$. Plasma lipid concentrations, including total cholesterol (TC), high-density lipoprotein cholesterol (HDL), lowdensity lipoprotein cholesterol (LDL), and triglycerides (TG), were determined using an autoanalyzer (Cobas 6000; Roche, Nakakojo, Japan) in accordance with the manufacturer's procedures.

\section{Immunofluorescence staining}

Immunofluorescence staining was performed as previously described [14]. In brief, after treatment with $3 \% \mathrm{H}_{2} \mathrm{O}_{2}$ for $15 \mathrm{~min}$ and $10 \%$ normal goat serum for 30 min, sections or cells were incubated overnight at $4{ }^{\circ} \mathrm{C}$ with the following primary antibodies: TET2 (1:50, Santa Cruz Biotechnology), 5hmC (1:50, EPIGENTEK), 5mC (1:50, EPIGENTEK), $\alpha$-smooth muscle actin $(1: 100$, ProteinTech), Beclin 1 (1:100, bioworld), LC3 (1:100, ProteinTech), p62 (1:50, Santa Cruz Biotechnology), VCAM-1 (1:50, Santa Cruz Biotechnology), ICAM-1 (1:50, Santa Cruz Biotechnology), MCP-1 (1:200, Santa Cruz Biotechnology), and IL-1 $\beta$ (1:200, Santa Cruz Biotechnology). Sections or cells were then incubated with cy3-conjugated secondary antibody for $1 \mathrm{~h}$ at room temperature. Thereafter, the samples were counterstained with 4',6-diamidino-2-phenylindol (DAPI) for the nuclei, followed by recording with a fluorescence microscope (IX70; Olympus, Tokyo).

\section{TET2 overexpression or knockdown in endothelial cells}

HUVECs were seeded at $4 \times 10^{5}$ cells/well in a six-well plate and then transfected with $5 \mu \mathrm{g}$ of TET2 overexpression plasmid or TET2 shRNA plasmid (OriGene Technologies Inc.) using Lipofectamine LTX (Invitrogen) in accordance with the manufacturer's instruction. After 1 $\mathrm{h}$, the transfection mixture was replaced with fresh growth medium. Any subsequent experiment on transfected cells was conducted $24 \mathrm{~h}$ after transfection.

\section{mRFP-GFP-LC3 adenovirus infection}

mRFP-GFP-LC3 adenoviral vectors were obtained from HanBio Technology Co. Ltd. (HanBio, Shanghai, China). After reaching 50\%-70\% confluence in 24well plates, cells were infected with mRFP-GFP-LC3 adenovirus in accordance with the manufacturer's instructions. In brief, HUVECs were incubated with growth medium supplied with the adenoviruses for 2 $\mathrm{h}$ at $37^{\circ} \mathrm{C}$ and then incubated with a new medium for another $24 \mathrm{~h}$ at $37^{\circ} \mathrm{C}$. Autophagic flux was recorded with a fluorescence microscope (IX70; Olympus, Tokyo).

\section{Validation of differentially methylated genomic regions using bisulfite sequencing}

Two differential CpG-rich regions of the Beclin 1 promoter were selected for bisulfite sequence. In brief, $1 \mu \mathrm{g}$ of genomic DNA was bisulfite-converted using the EZ-96 DNA Methylation Kit (Zymo Research) in accordance with the manufacturer's protocol. Primers (5'-GTTTAGGTTGGAGTGTAGTGGTATG-3', 5'-AACCACTACACTCCAACCTAAAC-3', length 325; 5'-GAGTAGTTGGGATTAAGTTGGGATT3' 5'-ACTCCTAATCCACAAACTCACAAAC-3', length 343) were designed using MethPrimer (http:// www.urogene.org/cgi-bin/methprimer/methprimer.cgi). The PCR products were purified using SK8141 PCR Purification (Qiagen), cloned to pUC18-T Vector Systems, and then transformed to SK9307 cells. Independent white colonies (10-20) were selected and sequenced in GenomeLab ${ }^{\text {TM }}$ GeXP Genetic Analysis System (Beckman Coulter). The bisulfite sequencing DNA methylation analysis software was used to analyze the sequencing data. The average of methylation percentage at each $\mathrm{CpG}$ site in each experimental group was used for analysis.

\section{Western blotting analysis}

Cells were lysed, and protein was qualified using the BCA method as previously described [15]. Equal amounts $(100 \mu \mathrm{g})$ of total protein were subjected to $10 \%$ sodium dodecyl sulfide-polyacrylamide gel electrophoresis and then transferred onto polyvinylidene difluoride membranes (Millipore, Bedford, MA). The membranes were incubated overnight at $4{ }^{\circ} \mathrm{C}$ with antiTET2 (1:200 diluted), anti-Beclin 1 (1:1000 diluted), anti-LC3 (1:1000 diluted), anti-p62 (1:200 dilution), antiVCAM-1(1:1000 dilution), anti-ICAM-1 (1:200 dilution), anti-MCP-1 (1:200 dilution), anti-IL-1 $\beta$ (1:200 dilution), or anti-GAPDH (1:1000 dilution) antibody. Then, the corresponding secondary antibody (peroxidase-conjugated anti-mouse or antigoat) was applied for $2 \mathrm{~h}$. Enhanced chemiluminescence reagents (Perkin Elmer, Waltham, MA, USA) were used to detect the targeted antigen. The abundance of the targeted protein was analyzed using Labwork image analysis software. All experiments were performed at least three times.

\section{Statistical analysis}

Data were presented as mean \pm SD. The unpaired Student's $t$ test or ANOVA was used to evaluate the 
significance of the differences. The $\mathrm{CpG}$ methylation rates of the Beclin 1 gene promoter were analyzed by chisquare test. $P<0.05$ was considered to indicate statistical significance.

\section{ACKNOWLEDGMENTS AND FUNDING}

This work was supported by the grants from the National Natural Science Foundation of China $(81370378,81641019,81670429,81541005)$, the Key Project of Science and Technology Department of Hunan Province (2015JC3081,2015SK2038), the Visiting Scholar Foundation of Key Laboratory of Biorheological Science and Technology (Chongqing University), Ministry of Education(CQKLBST-2015-004), and the Construct Program of the Key Discipline in Hunan Province, the Program for Science and Technology Innovative Research Team in Higher Educational Institutions of Hunan Province (2008-244), and Zhengxiang Scholar Program of University of South China (2014-004).

\section{CONFLICTS OF INTEREST}

The authors declare they have no conflicts of interest

\section{REFERENCES}

1. De Meyer GR, Grootaert MO, Michiels CF, Kurdi A, Schrijvers DM, and Martinet W. Autophagy in vascular disease. Circ Res. 2015; 116: 468-79. doi: 10.1161/ CIRCRESAHA.116.303804.

2. Guo F, Li X, Peng J, Tang Y, Yang Q, Liu L, Wang Z, Jiang Z, Xiao M, Ni C, Chen R, Wei D, and Wang GX. Autophagy regulates vascular endothelial cell eNOS and ET-1 expression induced by laminar shear stress in an ex vivo perfused system. Ann Biomed Eng. 2014; 42: 1978-88. doi: 10.1007/s10439-014-1033-5.

3. Xiong Y, Yepuri G, Forbiteh M, Yu Y, Montani JP, Yang Z, and Ming XF. ARG2 impairs endothelial autophagy through regulation of MTOR and PRKAA/AMPK signaling in advanced atherosclerosis. Autophagy. 2014; 10: 2223-38. doi: $10.4161 / 15548627.2014 .981789$.

4. Bai H, Inoue J, Kawano T, and Inazawa J. A transcriptional variant of the LC3A gene is involved in autophagy and frequently inactivated in human cancers. Oncogene. 2012; 31: 4397-408. doi: 10.1038/onc.2011.613.

5. Li Z, Chen B, Wu Y, Jin F, Xia Y, and Liu X. Genetic and epigenetic silencing of the beclin 1 gene in sporadic breast tumors. BMC Cancer. 2010; 10: 98. doi: 10.1186/14712407-10-98.

6. Lund G, Andersson L, Lauria M, Lindholm M, Fraga MF, Villar-Garea A, Ballestar E, Esteller M, and Zaina S. DNA methylation polymorphisms precede any histological sign of atherosclerosis in mice lacking apolipoprotein E. J Biol Chem. 2004; 279: 29147-54.
7. Dunn J, Qiu H, Kim S, Jjingo D, Hoffman R, Kim CW, Jang I, Son DJ, Kim D, Pan C, Fan Y, Jordan IK, and Jo H. Flow-dependent epigenetic DNA methylation regulates endothelial gene expression and atherosclerosis. J Clin Invest. 2014;124: 3187-99. doi: 10.1172/JCI74792.

8. Hu L, Lu J, Cheng J, Rao Q, Li Z, Hou H, Lou Z, Zhang L, Li W, Gong W, Liu M, Sun C, Yin X, Li J, Tan X, Wang P, et al. Structural insight into substrate preference for TETmediated oxidation. Nature. 2015;527:118-22. doi: 10.1038/ nature 15713

9. Murata A, Baba Y, Ishimoto T, Miyake K, Kosumi K, Harada K, Kurashige J, Iwagami S, Sakamoto Y, Miyamoto Y, Yoshida N, Yamamoto M, Oda S, Watanabe M, et al. TET family proteins and 5-hydroxymethylcytosine in esophageal squamous cell carcinoma. Oncotarget. 2015; 6: 23372-82. doi: 10.18632/oncotarget.4281.

10. Ko M, Bandukwala HS, An J, Lamperti ED, Thompson EC, Hastie R, Tsangaratou A, Rajewsky K, Koralov $\mathrm{SB}$, and Rao A. Ten-Eleven-Translocation 2 (TET2) negatively regulates homeostasis and differentiation of hematopoietic stem cells in mice. Proc Natl Acad Sci U S A. 2011;108:14566-71. doi: 10.1073/pnas.1112317108.

11. Ko M, and Rao A. TET2: epigenetic safeguard for HSC. Blood. 2011; 118: 4501-3. doi: 10.1182/ blood-2011-08-373357.

12. Shide K, Kameda T, Shimoda H, Yamaji T, Abe H, Kamiunten A, Sekine M, Hidaka T, Katayose K, Kubuki Y, Yamamoto S, Miike T, Iwakiri H, Hasuike S, Nagata $\mathrm{K}$, Marutsuka $\mathrm{K}$, et al. TET2 is essential for survival and hematopoietic stem cell homeostasis. Leukemia. 2012; 26: 2216-23. doi: 10.1038/leu.2012.94.

13. Liu R, Jin Y, Tang WH, Qin L, Zhang X, Tellides G, Hwa J, Yu J, and Martin KA. Ten-eleven translocation-2 (TET2) is a master regulator of smooth muscle cell plasticity. Circulation. 2013; 128:2047-57. doi: 10.1161/ CIRCULATIONAHA.113.002887.

14. Li G, Peng J, Liu Y, Li X, Yang Q, Li Y, Tang Z, Wang Z, Jiang Z, and Wei D. Oxidized low-density lipoprotein inhibits THP-1-derived macrophage autophagy via TET2 down-regulation. Lipids. 2015; 50:177-83. doi: 10.1007/ s11745-014-3977-5 .

15. Yang Q, Li X, Li R, Peng J, Wang Z, Jiang Z, Tang $\mathrm{X}$, Peng Z, Wang $\mathrm{Y}$, and Wei D. Low Shear Stress Inhibited Endothelial Cell Autophagy Through TET2 Downregulation. Ann Biomed Eng. 2016; 44: 2218-27. doi: 10.1007/s10439-015-1491-4.

16. Wang KY, Tanimoto A, Guo X, Yamada S, Shimajiri S, Murata Y, Ding Y, Tsutsui M, Kato S, Watanabe T, Ohtsu H, Hirano K, Kohno K, et al. Histamine deficiency decreases atherosclerosis and inflammatory response in apolipoprotein E knockout mice independently of serum cholesterol level. Arterioscler Thromb Vasc Biol. 2011; 31: 800-7. doi: 10.1161/ATVBAHA.110.215228.

17. Nigro P, Satoh K, O’Dell MR, Soe NN, Cui Z, Mohan A, Abe J, Alexis JD, Sparks JD, and Berk BC. Cyclophilin A 
is an inflammatory mediator that promotes atherosclerosis in apolipoprotein E-deficient mice. J Exp Med. 2011; 208: 53-66. doi: 10.1084/jem.20101174.

18. Martinet W, and De Meyer GR. Autophagy in atherosclerosis: a cell survival and death phenomenon with therapeutic potential. Circ Res. 2009;104:304-17. doi: 10.1161/CIRCRESAHA.108.188318.

19. Peng N, Meng N, Wang S, Zhao F, Zhao J, Su L, Zhang S, Zhang Y, Zhao B, and Miao J. An activator of mTOR inhibits oxLDL-induced autophagy and apoptosis in vascular endothelial cells and restricts atherosclerosis in apolipoprotein E(-)/(-) mice. Sci Rep. 2014; 4: 5519. doi: $10.1038 /$ srep05519.

20. Nussenzweig SC, Verma S, and Finkel T. The role of autophagy in vascular biology. Circ Res. 2015; 116: 480-8. doi: 10.1161/CIRCRESAHA.116.303805.

21. Abderrazak A, Couchie D, Mahmood DF, Elhage R, Vindis C, Laffargue M, Mateo V, Buchele B, Ayala MR, El Gaafary M, Syrovets T, Slimane MN, Friguet B, Fulop T, Simmet T, El Hadri K, et al. Anti-inflammatory and antiatherogenic effects of the NLRP3 inflammasome inhibitor arglabin in ApoE2.Ki mice fed a high-fat diet. Circulation. 2015; 131: 1061-70. doi: 10.1161/CIRCULATIONAHA.114.013730.

22. Li Z, Cai X, Cai CL, Wang J, Zhang W, Petersen BE, Yang FC, and $\mathrm{Xu}$ M. Deletion of Tet2 in mice leads to dysregulated hematopoietic stem cells and subsequent development of myeloid malignancies. Blood. 2011; 118: 4509-18. doi: 10.1182/blood-2010-12-325241.

23. Wirawan E, Lippens S, Vanden Berghe T, Romagnoli A, Fimia GM, Piacentini M, and Vandenabeele P. Beclin1: a role in membrane dynamics and beyond. Autophagy. 2012; 8: 6-17. doi: 10.4161/auto.8.1.16645.
24.Saitoh T, Fujita N, Jang MH, Uematsu S, Yang BG, Satoh T, Omori H, Noda T, Yamamoto N, Komatsu M, Tanaka K, Kawai T, Tsujimura T, et al. Loss of the autophagy protein Atg16L1 enhances endotoxin-induced IL-1beta production. Nature. 2008; 456: 264-8. doi: 10.1038/nature07383.

25.Harris J, Hartman M, Roche C, Zeng SG, O'Shea A, Sharp FA, Lambe EM, Creagh EM, Golenbock DT, Tschopp J, Kornfeld H, Fitzgerald KA, and Lavelle EC. Autophagy controls IL-1 $\beta$ secretion by targeting Pro-IL$1 \beta$ for degradation. J Biol Chem. 2011; 286: 9587-97. doi: 10.1074/jbc.M110.202911.

26.Zhou R, Yazdi AS, Menu P, and Tschopp J. A role for mitochondria in NLRP3 inflammasome activation. Nature. 2011; 469: 221-5. doi: 10.1038/nature09663.

27. Razani B, Feng C, Coleman T, Emanuel R, Wen H, Hwang S, Ting JP, Virgin HW, Kastan MB, and Semenkovich CF. Autophagy links inflammasomes to atherosclerotic progression. Cell Metab. 2012; 15: 534-44. doi: 10.1016/j. cmet.2012.02.011.

28. Ichiyama K, Chen T, Wang X, Yan X, Kim BS, Tanaka S, Ndiaye-Lobry D, Deng Y, Zou Y, Zheng P, Tian Q, Aifantis I, Wei L, et al. The methylcytosine dioxygenase Tet2 promotes DNA demethylation and activation of cytokine gene expression in T cells. Immunity. 2015; 42: 613-26. doi: 10.1016/j.immuni.2015.03.005.

29. Zhang Q, Zhao K, Shen Q, Han Y, Gu Y, Li X, Zhao D, Liu Y, Wang C, Zhang X, Su X, Liu J, Ge W, et al. Tet2 is required to resolve inflammation by recruiting Hdac2 to specifically repress IL-6. Nature. 2015; 525: 389-93. doi: $10.1038 /$ nature 15252 . 